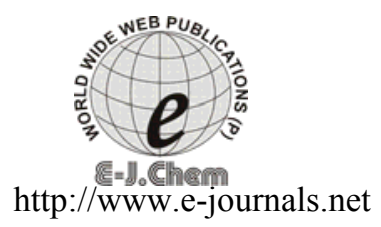

ISSN: 0973-4945; CODEN ECJHAO

E-Journal of Chemistry

2011, 8(S1), S488-S494

\title{
Evaluation of Plants and Weeds Extract on the Corrosion Inhibition of Mild Steel in Sulphuric Acid
}

\author{
ABIDA BEGUM \\ Department of Chemistry, P.E.S School of Engineering \\ Bengaluru, 560100, Karnataka, India \\ drabid.drabida@gmail.com
}

Received 11 April 2011; Accepted 2 July 2011

\begin{abstract}
Experiments were performed in order to determine the inhibitive effects of extracts of plants and weeds namely Parthenium hysterophorus, Dathura stromonium, Azadirachta indica, Helianthus annuus leaves extract for mild steel in sulphuric acid by using weight loss and thermometric technique. Results demonstrated that, all the experimental inhibitors show an adsorption on steel surface according to Langmuir's isotherm. The inhibition efficiency increased with increase in the concentration of all tested inhibitors to attain a maximum value at $1.0 \%$. Free energy values for adsorption process show that the process is spontaneous. The kinetic treatment of the results shows first order kinetics.
\end{abstract}

Keywords: Dathura stromonium, Azadirachta indica, Helianthus annuus, Parthenium hysterophorus, Corrosion inhibitors, Acidic medium

\section{Introduction}

Corrosion specifically refers to any process involving the deterioration or degradation of metal components. Corrosion is the primary means by which metals deteriorate. Most metals corrode on contact with water (and moisture in the air), acids, bases, salts, oils, aggressive metal polishes and other solid and liquid chemicals. Metals will also corrode when exposed to gaseous materials like acid vapours, formaldehyde gas, ammonia gas and sulfur containing gases. Inhibitors are generally used to protect materials against deterioration from corrosion. Most of the well-known acid inhibitors used in industry are organic compounds having multiple bonds in their molecules that mainly contain nitrogen, sulphur, oxygen atoms through which they get adsorbed on the metal surfacel effective ${ }^{1}$. Corrosion inhibitors are of great practical importance, being extensively employed in minimizing metallic waste in engineering materials ${ }^{2,3}$. Higher plants and their extracts are gaining growing interest because of their cost effective and eco-friendly attributes. Plant extracts have played significant role in the inhibition of corrosion. 
Azadirachta indica., neem is distributed widespread in the world. The chemical constituents in it contain many bioactive compounds that can be extracted from neem, including alkaloids, flavonoids, tri-terpenoids, phenolic compounds, carotenoids, steroids and ketones. azadirachtin, a mixture of seven isomeric compounds labeled as azadirachtin AG and Azadirachtin $E$ is more effective. Other compounds than azadirachtin having biological activity are salannin, volatile oils, meliantriol and nimbin.

Helianthus annuus, (composite), is distributed worldwide. The plant contains an oleic acid and the new triacyl glycerol was identified as isomers of oleic acid from high saturated sunflowers. It also contains various alkaloids, glycosides, saponins, cardiac glycosides, tannins, fixed oils and simple phenolic.

Allium cepa (Liliaceae), vernacular name: Basal, is distributed world wide. It contains numerous organic sulfur compounds, including trans-S-(1- propenyl) cysteine sulfoxide, S-methyl-cysteine sulfoxide, $S$ - propylcysteine sulfoxide and cycloalliin; flavonoids; phenolic acids; sterols including cholesterol, stigma sterol, $b$-sitosterol; saponins; sugars and a trace of volatile oil composed mainly of sulfur compounds, including dipropyl disulfide.

Parthenium hystophrous L maily contains sequiterepene lactone is used externally for skin disorders and also possesses antitumor properties. The root is useful to arrest dysentery. Detection of the plant is often taken internally as a remedy for a wide variety of ailment and its leaf yields an essential oil.

\section{Experimental}

Mild steel metal (the percentage elemental composition was found to be, $\mathrm{C}(0.048 \%), \mathrm{Mn}$ (0.335\%), Si (0.029\%), P(0.041\%), S (0.025\%), Cr (0.050\%), Mo (0.016\%), Ni (0.019\%) and $\mathrm{Fe}(99.437 \%)$ having a surface area of $5 \times 1 \mathrm{~cm}^{2}$ were cut from a large sheet. The specimens were pickled in 5\% sulphuric acid for about 2 minutes and washed with distilled water and polished successively with emery sheets, degreased and dried. The weight of specimen were noted and then immersed in test solution containing various concentration of inhibitors at room temperature $300 \mathrm{~K}, 303 \mathrm{~K} 309 \mathrm{~K}$ and $313 \mathrm{~K}$. After the duration of $2 \mathrm{~h}$ in $1.5 \mathrm{~N}$ sulphuric acid, the specimens were removed from test solution, pickled, dried and weighed finally the difference in weight were noted and the corrosion rates were calculated ${ }^{1}$. Distilled water and AR grade $\mathrm{H}_{2} \mathrm{SO}_{4}$ were used for preparing solutions. The corrosion inhibitor solution of the plant extract as $0.2,0.4,0.6,0.8$ and $1 \%$ was prepared.

The fresh leaves of Parthenium hysterophorus, Dathura stromonium, Azadirachta indica and Helianthus annuus were collected, shade dried and powdered. Plant material was thoroughly washed with tap water to remove soil and dust, sprayed with distilled water, dried in an oven at $80^{\circ} \mathrm{C}$ to a constant weight. The extract was prepared by refluxing $10 \mathrm{~g}$ of powdered dry leaves in $0.5 \mathrm{~N}$ sulphuric acid for $1 \mathrm{~h}$ and kept overnight. Then it was filtered and the volume of the filtrate was made up to $50 \mathrm{~mL}$ using the same acid and this was taken as stock solution.

\section{Results and Discussion}

The corrosion behaviour of mild steel in sulphuric acid (Table 1 and Figure $1 \& 2$ ) and analysed by weight loss method at $300 \mathrm{~K}$ and also at the given concentrations of inhibitors $(0.2 \%$ to $1.0 \%)$. The experiment was also conducted at different immersion time to study the rate of reaction ${ }^{4}$. The values of the rate constant was calculated using the first order rate law, $\mathrm{k}=(2.303 / \mathrm{t}) \log \left(\left[\mathrm{A}_{0} / \mathrm{A}\right]\right)$, where $\left[\mathrm{A}_{0}\right]$ is the initial mass of the metal and $[\mathrm{A}]$ is the mass corresponding to time' $t$ '. The half-life $\left(t_{1 / 2}\right)$ was calculated using the relationship ${ }^{5}, t_{1 / 2}=0.693 / \mathrm{k}$. 
The values of rate constant and half-life $\left(\mathrm{t}_{1 / 2}\right)$ obtained from the above relations were summarized in Table 1. Half life values were found to be constant at different immersion time. The constant value of the rate constant further confirmed that the corrosion of mild steel in sulphuric acid solution in presence of biomaterial follows first order reaction.

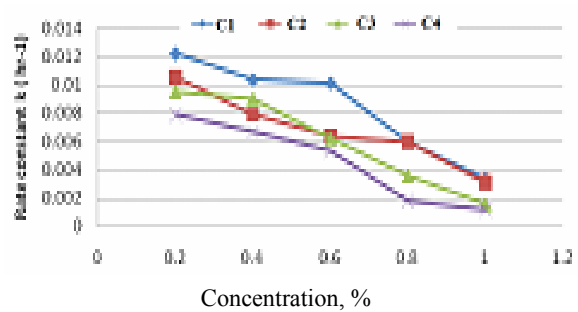

Figure 1. Inhibitor concentration vs rate constant

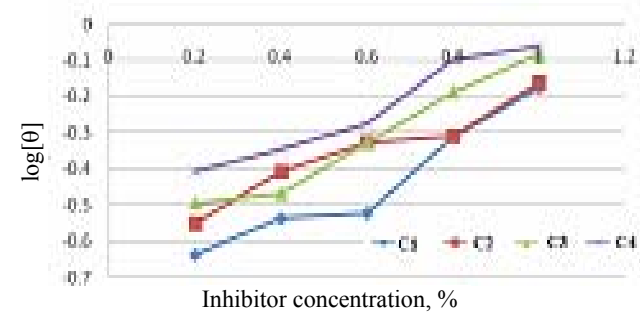

Figure 2. Inhibitor concentration $v s \log (\theta)$

Table 1. Effect of plant biomasses on mass loss data for corrosion of mild steel in $1.5 \mathrm{~N}$ $\mathrm{H}_{2} \mathrm{SO}_{4}$ at $300 \mathrm{~K}$

\begin{tabular}{cccccc}
\hline \multirow{2}{*}{ Inhibitor } & $\begin{array}{c}\text { Concentration, } \\
\%\end{array}$ & $\begin{array}{c}\text { Inhibition } \\
\text { efficiency, } \\
\text { I.E, } \%\end{array}$ & $\begin{array}{c}\text { Surface } \\
\text { coverage, } \\
\theta\end{array}$ & $\begin{array}{c}\text { Rate } \\
\text { constant } \\
\mathrm{K}, \mathrm{h}^{-1}\end{array}$ & $\begin{array}{c}\text { Half } \\
\text { life } \mathrm{t}_{1 / 2}, \\
\mathrm{~h}\end{array}$ \\
\cline { 2 - 6 } & $\begin{array}{c}\text { Blank } 1.5 \mathrm{~N} \\
\mathrm{H}_{2} \mathrm{SO}_{4}\end{array}$ & - & - & - & - \\
Parthenium & 0.2 & 23.09 & 0.23 & 0.01222 & 56.73 \\
hysterophorus Leaves & 0.4 & 28.77 & 0.29 & 0.01038 & 66.75 \\
& 0.6 & 29.66 & 0.30 & 0.01013 & 68.42 \\
& 0.8 & 49.02 & 0.49 & 0.00594 & 116.63 \\
Dathura stromonium & 1.0 & 66.79 & 0.67 & 0.00336 & 205.96 \\
Leaves & 0.2 & 28.24 & 0.28 & 0.01054 & 65.76 \\
& 0.4 & 38.72 & 0.39 & 0.00791 & 87.63 \\
Azadirachta indica & 0.6 & 46.54 & 0.47 & 0.00638 & 108.70 \\
Leaves & 0.8 & 48.85 & 0.49 & 0.00597 & 116.04 \\
& 1.0 & 69.09 & 0.69 & 0.00308 & 224.90 \\
& 0.2 & 31.79 & 0.32 & 0.00955 & 72.56 \\
& 0.4 & 33.75 & 0.34 & 0.00905 & 76.54 \\
& 0.6 & 47.25 & 0.47 & 0.00625 & 110.89 \\
Helianthus annuus & 0.8 & 65.19 & 0.65 & 0.00357 & 194.30 \\
Leaves & 1.0 & 82.59 & 0.83 & 0.00159 & 434.76 \\
& 0.2 & 38.72 & 0.39 & 0.00791 & 87.63 \\
& 0.4 & 44.76 & 0.45 & 0.00670 & 103.43 \\
& 0.6 & 52.58 & 0.53 & 0.00536 & 129.32 \\
& 0.8 & 80.28 & 0.80 & 0.00183 & 378.62 \\
& 1.0 & 86.68 & 0.87 & 0.00119 & 581.58 \\
\hline
\end{tabular}

From the table and graph plot, it was observed that the weight loss of mild steel in the acid decreases with increasing concentration of inhibitors, which suggest that the organic compounds present in the selected plants are corrosion inhibitors for mild steel in $1.5 \mathrm{~N}$ sulphuric acid. From the data of weight loss method, corrosion rate was calculated using the equation 


$$
\mathrm{C} . \mathrm{R}(\mathrm{mpy})=\frac{436.095 \times 1000 \times \mathrm{W}}{\mathrm{A} \times \mathrm{T}}
$$

Where, $\mathrm{W}=$ Weight loss in grams, $\mathrm{A}=$ Area of specimen in $\mathrm{cm}^{2} \mathrm{~T}=$ Exposure time in hours. The unit of the corrosion rate is in mills per year (mpy). Similarly, inhibition efficiency was calculated using the equation ${ }^{5}$.

$$
\text { IE \% }=\begin{gathered}
\text { weight loss without inhibitor }- \text { weight loss with inhibitor } \\
\text { Weight loss without inhibitor }
\end{gathered} \times 100
$$

The values of corrosion rate and inhibition efficiency in absence and presence of different concentration of inhibitor used in $1.5 \mathrm{~N}$ sulphuric acid at the given temperatures are shown in the Table 2.

Table 2. Corrosion inhibition behaviour of mild steel in $1.5 \mathrm{~N}$ sulphuric acid solution in absence and presence of plant biomaterial by weight loss measurement

\begin{tabular}{cccccc}
\hline Inhibitor & $\begin{array}{c}\text { Temperature, } \\
\text { K }\end{array}$ & I.E, \% & C.R mpy & $1000 / \mathrm{T}$ & $\log (\mathrm{CR})$ \\
\hline \multirow{4}{*}{ Blank } & 300 & - & 98243.48 & 3.3 & 4.99 \\
& 303 & - & 89312.26 & 3.25 & 4.95 \\
Parthenium & 309 & - & 137108.27 & 3.19 & 5.14 \\
hysterophorus & 313 & - & 162925.09 & 3.14 & 5.21 \\
& 300 & 66.80 & 32619.91 & 3.3 & 4.51 \\
& 303 & 65.82 & 30526.65 & 3.25 & 4.48 \\
Dathura stromonium & 309 & 63.36 & 50238.14 & 3.19 & 4.70 \\
& 313 & 63.06 & 60181.11 & 3.14 & 4.78 \\
& 303 & 69.11 & 30352.21 & 3.3 & 4.48 \\
Azadirachta indica & 308 & 66.41 & 30003.34 & 3.25 & 4.48 \\
& 313 & 61.58 & 52680.28 & 3.19 & 4.72 \\
& 300 & 61.88 & 62099.93 & 3.14 & 4.79 \\
Helianthus annuus & 303 & 80.60 & 17094.92 & 3.3 & 4.23 \\
& 309 & 77.99 & 30177.77 & 3.19 & 4.24 \\
& 313 & 76.98 & 37504.17 & 3.14 & 4.57 \\
& 300 & 86.68 & 13082.85 & 3.3 & 4.12 \\
& 303 & 81.15 & 16833.27 & 3.25 & 4.23 \\
& 309 & 71.88 & 38550.80 & 3.19 & 4.59 \\
\hline
\end{tabular}

From the Table 1 and 2 it is evident that, the corrosion rate was decreased with increasing concentration of inhibitor and inhibition efficiency with increasing the concentration of the inhibitor ${ }^{6}$. In addition, the maximum corrosion inhibition efficiency of plant biomaterial was increased from $0.2 \%$ to $1.0 \%$. Also the inhibitor efficiency of plant extract is compared at $1.0 \%$ concentration and at different temperatures. The rate of efficiency is high at $300 \mathrm{~K}$ when compared to $318 \mathrm{~K}$ respectively in $1.5 \mathrm{~N}$ sulphuric. It was concluded that Azadirachta indica (I.E $=82 \%)$ and Helianthus annuus (I.E $=86 \%)$ are the best inhibitor in mild steel corrosion in sulphuric acid medium at low temperature. The result demonstrated through the graph is a monolayer adsorption. A plot of $(\theta) v s$. log (C) gave a straight line (Figure 3 ). This indicates the system also obeys Temkin adsorption isotherm. 
Temperature change of the system involving mild steel in $1.5 \mathrm{~N}$ sulphuric acid was followed as a function of time in the absence and presence of different concentrations of plant biomaterial (Table 3 and Figure 4). The maximum temperature (Tm) measured in the free acid solution attained after time $(\mathrm{t})$ corresponds to a reaction number $(\mathrm{RN})^{7,8}$. Addition of biomaterial caused a decreased in the maximum temperature and an increase in the time required reaching it. This indicates that plant biomaterial retards the dissolution rate of mild steel in the acidic solution, presumably by its adsorption on the metal surface. The extent of inhibition depends on the degree of coverage of the metal by the adsorbed molecules.

Table 3. Variation of reaction number $\left(\mathrm{RN} \mathrm{k} \mathrm{min}^{-1}\right)$ at various concentrations of all four inhibitors in $1.5 \mathrm{~N}$ sulphuric acid solution in mild steel

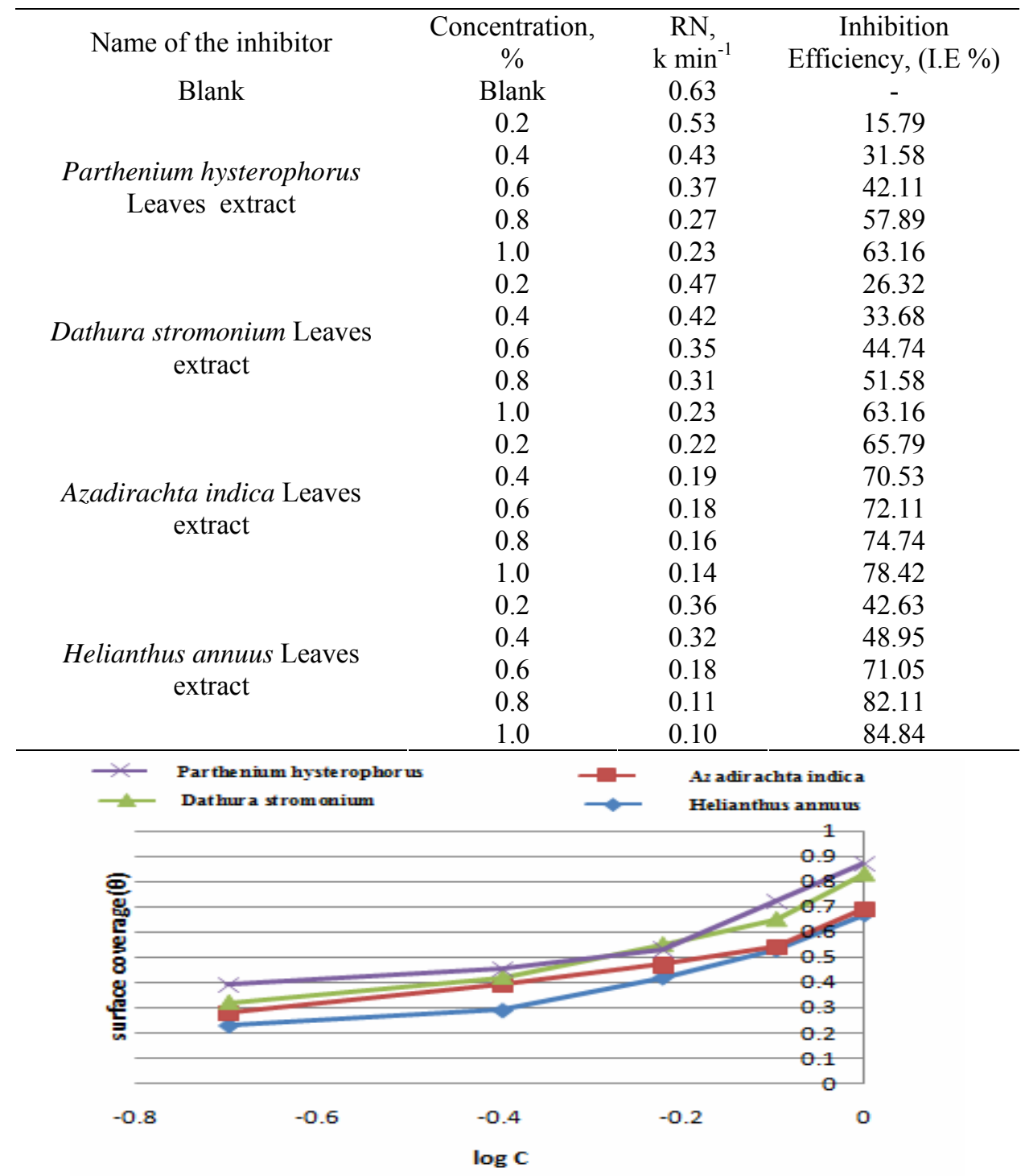

Figure 3. Tempkin adsorption isotherm for the given inhibitors 
Energy of activation (Ea) value was evaluated from Arrhenius equation. In the presence of inhibitor the Ea values of the inhibitor system was found to be higher than that of the uninhibited system (Table 4). The high Ea values indicated an efficient inhibiting action of the inhibitor. Higher activation energy for the corrosion process in the presence of inhibitor leads to a conclusion that probably the inhibitor is found to be adsorbed on the surface by specific adsorption process ${ }^{9}$.

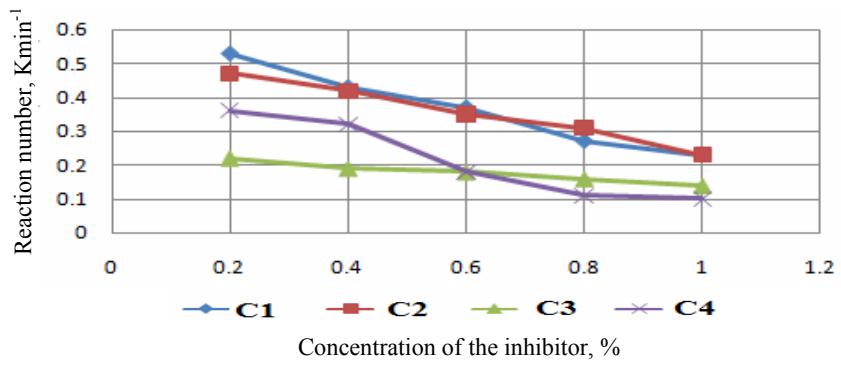

Figure 4. Inhibitor concentration (\%) vs. reaction number

Thermodynamic parameters like $\Delta \mathrm{G}, \Delta \mathrm{H}$ and $\Delta \mathrm{S}$ for adsorption of inhibitor were calculated and presented in Table 4. The change in free energy values indicate the interaction of inhibitor molecules on mild steel surface and a spontaneous adsorption of the inhibitor on the metal surface. The values of $\Delta \mathrm{H}$ and $\Delta \mathrm{S}$ infer that the adsorption of inhibitor on mild steel is enthalpic and entropic controlled.

Table 4. Calculated values of $\mathrm{E}_{\mathrm{a}}$ and $\Delta \mathrm{G}_{\text {ads }}^{0}$ for the corrosion of mild steel in $1.5 \mathrm{M} \mathrm{H}_{2} \mathrm{SO}_{4}$ containing the given inhibitor addition

\begin{tabular}{|c|c|c|c|c|c|c|c|}
\hline Inhibitor & $\begin{array}{c}-\mathrm{E}_{\mathrm{a}} \\
\mathrm{kJ} / \mathrm{mole}\end{array}$ & $\begin{array}{c}\Delta \mathrm{S}^{0} \\
\mathrm{JK}^{-1} / \text { mole }\end{array}$ & $\begin{array}{c}-\Delta \mathrm{H}^{0} \\
\mathrm{~kJ} / \mathrm{mole}\end{array}$ & \multicolumn{4}{|c|}{$\begin{array}{l}-\Delta \mathrm{G}_{\text {ads }}^{0} \text { at Various temperature, } \\
\mathrm{kJ} / \mathrm{mole}\end{array}$} \\
\hline Blank & 30.37 & - & - & - & - & - & - \\
\hline $\begin{array}{l}\text { Parthenium } \\
\text { hysterophorus }\end{array}$ & 36.42 & 0.07 & 71.65 & 49.98 & 49.74 & 48.83 & 49.23 \\
\hline $\begin{array}{c}\text { Dathura } \\
\text { stromonium }\end{array}$ & 42.24 & 0.25 & 126.9 & 52.23 & 51.01 & 48.07 & 49.08 \\
\hline $\begin{array}{l}\text { Azadirachta } \\
\text { indica }\end{array}$ & 45.34 & 0.13 & 100.85 & 61.81 & 60.96 & 6.11 & 60.1 \\
\hline $\begin{array}{l}\text { Helianthus } \\
\text { annuus }\end{array}$ & 72.35 & 0.75 & 289.28 & 64.86 & 61.33 & 55.4 & 55.58 \\
\hline Blank & 30.37 & - & - & - & - & - & - \\
\hline
\end{tabular}

\section{Conclusion}

The selected plant biomaterial showed good performance as corrosion inhibitor in sulphuric acid solution may be due to the formation of an insoluble protective surface film which suppresses the metal dissolution reaction. First order types of reaction were observed in the kinetic studies. The inhibition efficiency increased with increase in concentration of inhibitors for $0.2 \%$ to $1.0 \%$ and decreased with rise in temperature from $300 \mathrm{~K}$ to $318 \mathrm{~K}$. The maximum inhibition efficiency of selected plant biomaterial was Azadirachta indica (I.E $=82 \%$ ) s and Helianthus annuus (I.E $=86 \%$ ) respectively in $1.5 \mathrm{~N}$ sulphuric at $300 \mathrm{~K}[1.0 \%]$ for $2 \mathrm{~h}$ of immersion time. From this investigation effect of mild steel corrosion in plant biomaterial in sulphuric acid medium is very effective when the concentration is going on increased. 


\section{References}

1. Ajmal M, Rawath J and Quraishi MA, Anti- Corros Meth Mater., 1998, 45(6), 419.

2. Abida begum, Harikrishna, Veena K and Irfanulla Khan, E-J Chem., 2008 5(4), 774-761.

3. Abida begum and Harikrishna S, Proceedings of the National Symposium on Electrochemical Science and Technology, IISc., 2010, 13.

4. Abida Begum, Int J Pharm Sci Res Review, 2011, 10(1), 167-169.

5. $\quad$ Ronggang Hu, Andreas Ornberg and Jinshen Pan, J Electrochem Soc., 2009, 156.

6. Venkatachari G and Rajagopalan K S, Chem Age India, 1979, 30, 475.

7. Vishnudevan M and Natesan M, Bull Electrochem., 2000, 16, 49.

8. Upadhyay R K and Mathur S P, E- J Chem., 2007, 4(3), 408-414.

9. Umoren S A, Obot I B and Ebenso E E, E- J Chem., 2008, 5(2), 355. 


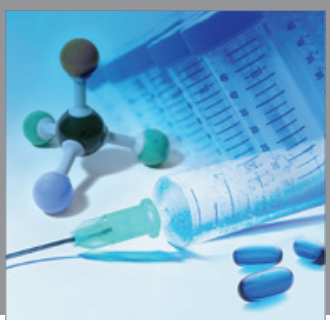

International Journal of

Medicinal Chemistry

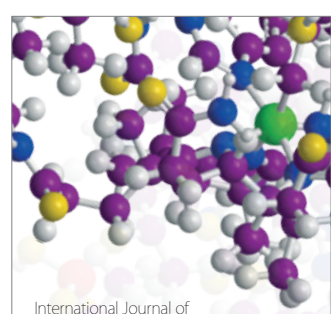

Carbohydrate Chemistry

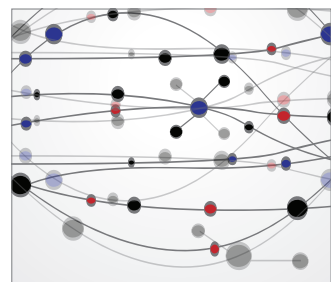

The Scientific World Journal
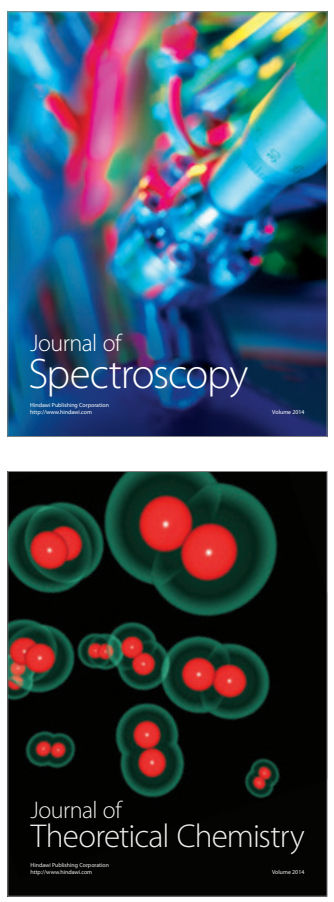
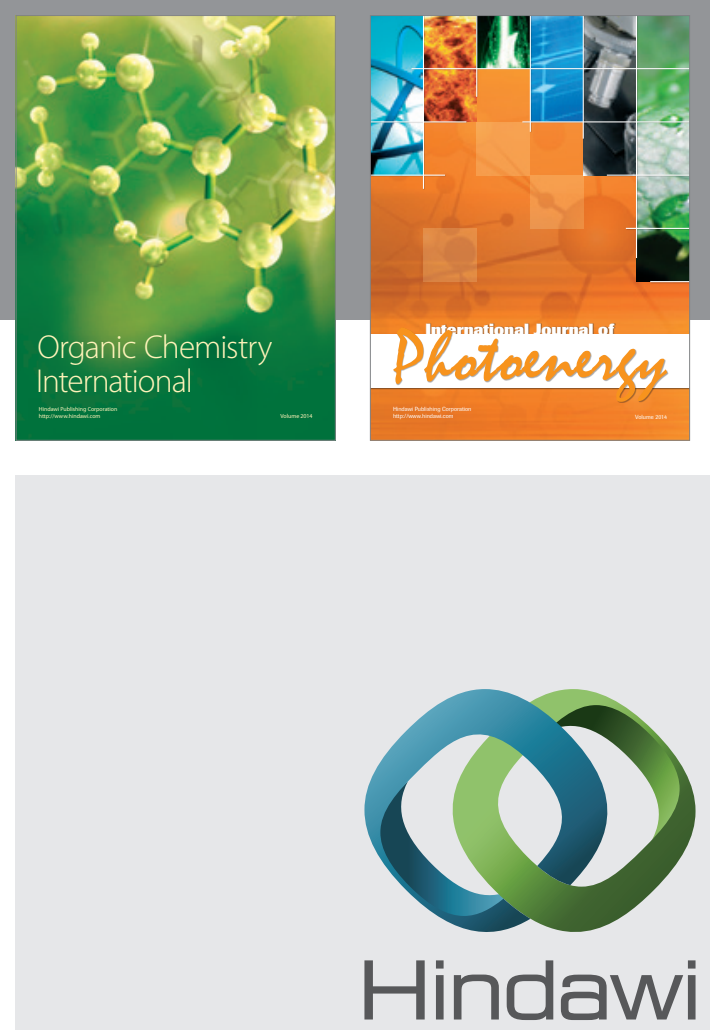

Submit your manuscripts at

http://www.hindawi.com
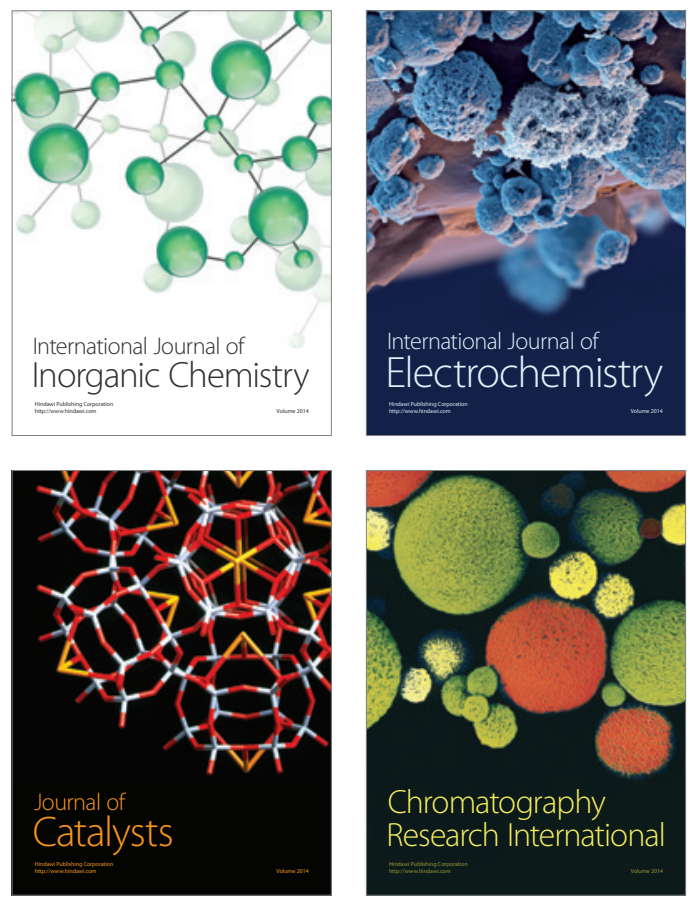
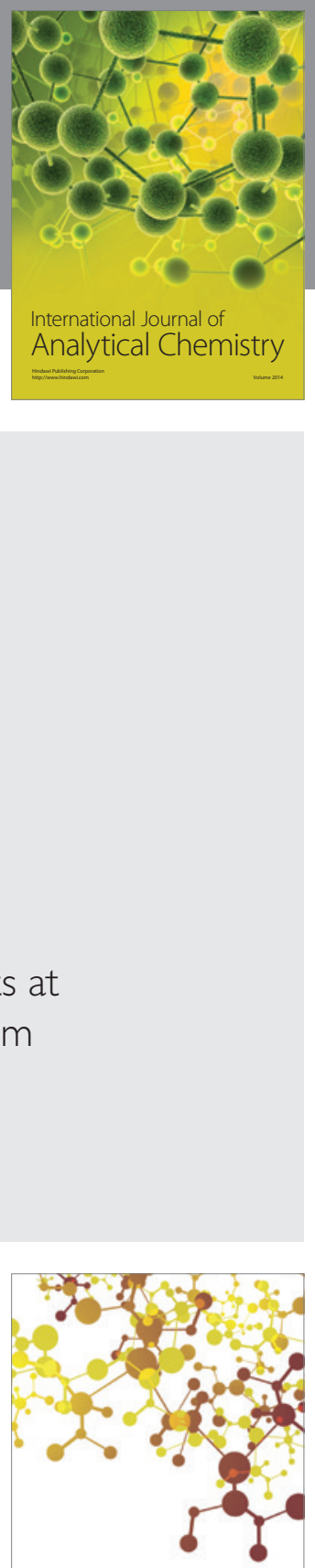

Journal of

Applied Chemistry
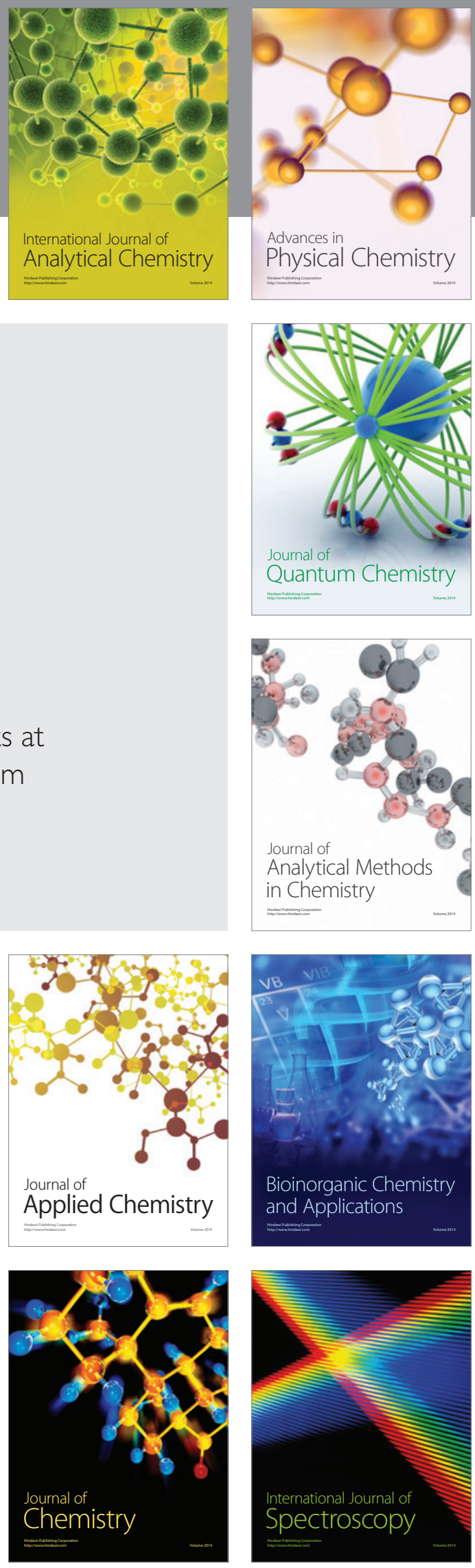